\title{
ON THE \\ LOSS OF POWER IN THE SCREW-PROPELLER, AND THE MEANS OF IMPROVING ITS EFFICIENCY.
}

By THE HoN. R. C. PARSONS, OF LoNDON.

Improvements in the Screw-Propeller, since its first invention, which seems to have originated with the Chinese, have been innumerable. It is surprising however that even up to the present time science, which has assisted so much in reducing mechanical invention to fixed laws, has in a great measure failed to discover fixed rules for the design of a screw-propeller for any individual ship; and the adjustment of the pitch of the blades, their number, \&ce, are left in a great measure to chance.

Having devated a good deal of time to the investigation of the laws which govern the flow of water through centrifugal pumps and turbines, and having made a large number of experiments upon these machines (some of which are published in the Proceedings of the Institution of Civil Engineers, vol. xlvii.), the author turned his attention to the consideration of the principles which affect the action of the screw-propeller. From the above experiments he was satisfied that it was of very great importance that the blades of the fan in these pumps should meet the water in a direction tangential to their surface, and that they should gradually impart a rotary motion to the water passing along them. But what seemed of still greater importance, for ensuring a high efficiency in the centrifugal pump, was that the water escaping from the fan should receive no sudden shock in passing to the discharge pipe, and also that its velocity should be reduced as gradually as possible. Applying these principles to the improvement of the screw-propeller, the author was led to the opinion that a higher efficiency could be obtained. with a propeller of a somewhat novel construction, which will be described in detail. This idea arose from the following considerations. 
In the case of every screw-propeller, whatever its form, a considerable amount of rotary motion is of necessity imparted to the water as it passes the blades. In screw-steamers of rather shallow draught, with engines running at a high speed, the helix of rotating water in the wake of the propeller is clearly visible at the stern. This rotation of the water can be traced to three distinct causes:-

(1) The pressure exerted against the water by the flat surface of the blades as they cut through it, which has the effect of propelling the water in a direction perpendicular to their surface; this action evidently occurs whether there is friction or not between the surface of the blades and the water.

(2) The skin friction between the surface of the blades and the water.

(3) The fact that the water displaced by the blades is not able to flow rapidly enough into the spaces previously occupied by them; in consequence of which eddies are formed, and a large volume of water is drawn forwards in the wake of the vessel. This last cause is probably greater than the first two put together; and at speeds of from 70 to 80 feet per second, which are common velocities for the extremities of the propeller blades in large vessels, this eddying rotation of the water becomes very intense. In a paper read before the Institution of Naval Architects in 1877 by Mr. Howden this last source of loss is discussed at length; but unfortunately no experiments seem to have been made by him, to determine its amount and the rate of its increase at high speeds.

In order to utilise. this rotary velocity of the water, various contrivances have been suggested: among the most successful of which was Mr. Arthur Rigg's invention in 1864. In this design the propeller was made a portion of an Archimedean screw with two threads. Abaft the propeller were six guide-blades, attached to the rudder-post, and so curved as to meet the effluent water at the same angle at which it left the propeller. This contrivance, although the experiments upon it seem to have been tolerably successful, has not, as far as the author is aware, met with much support either in the navy or in the mercantile marine.

Some experiments have recently been carried out by the author 
upon a propeller designed to reduce the losses above mentioned. The preliminary trials were made with a propeller 3 in. in diameter, which is now exhibited. In order to place it in a position similar to that of the propeller at the stern of a ship, it was fitted into a trough circular in plan, having a straight portion in which the propeller was placed. Surrounding the propeller was a brass tube, $3 \frac{1}{32}$ in, in diameter, and abaft it were fitted four guide-blades. When the propeller was rotated, the water was set in motion in the circular trough from the hinder end of the propeller, and flowing round the trough arrived at the front of the propeller with a considerable velocity, as in the case of a ship moving through the water.

In order to determine the amount of power required to rotate the propeller, the weight dynamometer, previously described in Proceedings 1879, p. 263, and shown in Fig. 6, Plate 29, was constructed. The velocity of the stream generated in the trough was measured by means of the head maintained in a glass tube, which was fixed with its orifice facing the stream issuing from the propeller, and at a definite distance from it. In making an experiment, the dynamometer was loaded with a definite weight, and the propeller rotated at such a. speed that the weight would just rise; the revolutions were then counted, and the head of water in the glass tube was measured. Various forms of propeller were tried in this trough; but as the apparatus was on such a small scale, and not constructed very accurately, no reliable quantitative results could be obtained, although the comparative trials showed an increase of efficiency in favour of the new form of propeller fitted with guide-blades.

After making these preliminary experiments, the author was. enabled, through the kindness of Mr. William Anderson, of Messrs. Easton and Anderson, to carry out a trial on a larger scale, with a propeller of $3 \mathrm{ft} .6$ in. diameter. The forms of the propeller and of the guide-blades were those which had been found to give the best. results with the model in the preliminary trials, and were as follows. The curves of the blades differ from most propellers in being helices increasing rapidly in pitch from their forward to their after edges, as shown in Figs. 1, 2, and 4, Plates 76 and 77; Fig. 1 represents a longitudinal section through the propeller and guide-blades, and 
Figs. 2 and 3 are two end elevations, one of the propeller and the other of the guide-blades. Fig. 4 is a section across one of the propeller-blades $A B$, and one of the guide-blades $C D$, at their outer extremities, and shows the centres and radii from and with which the curves are struck. In the propeller under consideration the pitch of the forward edge was 5.07 ft., and that of the terminal edge $15.92 \mathrm{ft}$. The pitch of the forward edge $A$ is designed so as to cut the water in a direction PA tangential to the surface of the blade; thus there is no shock or eddying motion produced in the water at its entrance upon the blades. The pitch of the blades being then increased, a rotation is gradually imparted to the water, which issues from the propeller with, a velocity considerably greater than from most propellers: it would issue in a direction $B Q$, assuming that there was no friction upon the propellerblades, but owing to the friction upon their surface it follows a path $B R$.

Abaft the propeller and attached to the rudder-post are four guide-blades G G, Figs. 1 and 3, Plate 76, which receive the water as it leaves the propeller with this high rotary velocity, and are curved in a helical form as shown in the section C D, Fig. 4, Plate 77, until they terminate at $\mathrm{D}$ in a direction parallel to the keel. Thus the rotary velocity produced in the water by the propeller is converted by the stationary guide-blades into a backward linear velocity parallel to the keel; and consequently the only losses which are occasioned are those due to the skin friction on the guide-blades, and the slight eddying motion produced by them. Surrounding the propeller and guide-blades is a cylindrical casing $\mathrm{N}, 3 \mathrm{ft} .6 \frac{1}{2}$ in. in diameter, which is attached to the rudder-post and stern-post, and also to the keel of the ship, as shown in Figs. 1 to 3, Plate 76 . This casing, besides confining the action of the propeller and guideblades to the volume of water enclosed within it, also supports the extremities of the guide-blades, as shown in Fig. 3.

In order to illustrate the advantages which may be derived from this combination, the case. of H.M.S. Lord Clyde may be taken as an 
example. The following are some of the principal data relating to that ship :-

\begin{tabular}{|c|c|c|c|c|c|c|}
\hline Diameter of Propeller & - & & & & & $23 \mathrm{ft}$. \\
\hline Diameter of boss & . & & & & & $6.5 \mathrm{ft}$. \\
\hline Revolutions per minute & . & . & & • & . & $64 \cdot 75$ \\
\hline Speed in knots per hour & . & • & & . & . & $13 \cdot 45$ \\
\hline Indicated Horse Power & . & . & & - & & 6064 \\
\hline Mean Pitch of propeller & & . & & . & & $23 \cdot 5 \mathrm{ft}$. \\
\hline
\end{tabular}

Here the theoretical advance of the propeller is $25 \cdot 36 \mathrm{ft}$. per second ( $23.5 \mathrm{ft}$. pitch $\times 64 \cdot 75$ revs. per min. $\div 60$ secs.); while the actual advance, or the speed of the ship, is $22.72 \mathrm{ft}$. per second $(13.45$ knots per hour $\times 6080 \mathrm{ft} . \div 3600$ secs. $)$; showing a slip of $25 \cdot 36-22 \cdot 72=2 \cdot 64 \mathrm{ft}$. per second, imparted to the water leaving the stern of the ship. The circumferential velocity of the extremities of the propeller-blades is $77.98 \mathrm{ft}$. per second ( $23 \mathrm{ft}$. diam. $\times 3 \cdot 1416$ $\times 64.75$ revs. per min. $\div 60$ secs.). Hence it will be seen from the triangle, Fig. 5, Plate 77, that the resultant velocity with which the extremities of the propeller-blades are forced through the water is $82 \mathrm{ft}$. per second $\left(\sqrt{77 \cdot 98^{2}+25 \cdot 36^{2}}\right)$. The consequent loss by skin friction, as well as that due to the displacement of the water by the blades, is very considerable.

With regard to the first of these two losses-namely that due to skin friction,-let it be assumed as an approximation that each blade of a propeller is a sector of a circle, of which let

$\theta$ be the angle.

$R$ external radius of propeller in feet.

$r$ radius of boss in feet.

$\omega$ angular velocity of propeller.

$y$ radius at which the loss of friction is a mean.

$x$ radius of any point on surface of propeller blade.

Now the loss by friction on each blade is proportionate to the quantity given by the formula

$$
\int_{r}^{n} \omega^{3} \theta x^{4} d x=\omega^{3} \theta \frac{R^{5}-r^{5}}{5} \quad \text { - (1) }
$$


This loss must then be equal to the friction due to the surface of the blade moved through the water at the mean speed : hence

$$
\omega^{3} \theta \frac{R^{3}-r^{5}}{5}=y^{3} \omega^{3} \theta \frac{R^{2}-r^{2}}{2} \text {. . . . }
$$

therefore

$$
y=\sqrt[3]{\frac{2}{5} \times \frac{R^{3}-r^{3}}{\hbar^{2}-r^{2}}} \quad \text {. . . }
$$

In the case of the Lord Clyde, when the preceding data are inserted into formula (3), the value of $y$ becomes $8.7 \mathrm{ft}$.

In the late Mr. Froude's report to the Admiralty upon surface friction, p. 10, it is stated that, at a speed of $600 \mathrm{ft}$. per minute (10 ft. per second), a surface of fine sand of 1 sq. $\mathrm{ft}$. area produces a frictional resistance of $0.69 \mathrm{lb}$; and for this surface the resistance varies as the square of the speed. Assuming that the surface of the propeller-blade resembles fine sand, then at a speed of $59 \mathrm{ft}$. per second (which from the preceding data is the circumferential velocity of the blade at the radius of mean friction, $8.7 \mathrm{ft}$.) the resistance per square foot of blade surface amounts to

$$
\left(\frac{59}{10}\right)^{2} \times 0 \cdot 69=24 \cdot 02 \mathrm{lbs} . \quad .
$$

In the case of the Lord Clyde the total surface of the blades is 203 square feet, and the mean distance travelled over is $59 \times 60=$ 3540 feet per minute; consequently the total loss by friction upon the blades amounts to

$$
\frac{3540 \times 24 \cdot 02 \times 208}{33000}=523 \text { H.P. }
$$

In addition to this, there is the loss due to the displacement of the water by the blades; but as the author is not aware that any extensive experiments have been carried out with a view to determine this loss at high speeds, he is not able to compate its amount.

Now if the propeller of the Lord Clyde, instead of revolving at a mean speed of 59 feet per second, which is that given by the investigation, had been driven at a mean speed of 47 feet per second, the loss by friction would have been reduced by half; and if the speed had been reduced to 30 feet per second, or half the original 
speed, the loss by friction would have been only 14 per cent. of its original value.

This reduction of speed in the propeller can easily be effected by increasing the pitch of its blades towards their after-edges, which, aș already explained, has the effect of imparting a considerable rotary motion to the water, to* be afterwards utilised by the guideblades.

In comparing the loss by friction upon the blades with this form of propeller and with one of the ordinary type, it may be assumed that the surface of the guide-blades is equal to that of the propellerblades. It has been seen that if the speed of the propeller be reduced from 59 to 30 feet per second, the surface friction is reduced in the ratio of 100 to 14 . Now if the loss by friction upon the guide-blades be the same as upon the propeller-blades, the total less by friction upon the blades will have been reduced in the ratio of 100 to 28 .

The next point of importance in considering a propeller of this nature is the reduction of the thrust upon the thrust-block, due to the application of guide-blades. The saving which may be expected to result from this seurce eannot be very trifling, when it is considered, for instance, that the thrust of the propeller of the Lord Clyde is resisted by a series of collars of 23 inches external diameter. By the application of the guide-blades the water which is leaving the propeller with a high rotary velocity is deflected into a linear stream parallel to the keel, and a forward thrust is imparted through the guide-blades to the ship. By this means, while retaining the same propelling force and therefore the same speed in the ship, the thrust upon the thrust-block can be reduced by about 40 per cent. Now with a reduction in the speed of the propeller of about 50 per cent., and at the same time a reduction of 40 per cent. in the thrust, thereis a resultant saving of about 70 per cent. in the friction upon the thrust-block.

Many experiments have from time to time been made with concentric propellers placed one abaft the other, the two rotating in opposite directions. It has always been urged by the inventors that an increase of efficiency over the ordinary propeller has been. 
obtained, but as far as the author is aware no accurate results of comparative trials have ever been published. The author has however been told as a fact that Whitehead torpedoes fitted with two propellers of this description have given an increased range with the same amount of compressed air as before.

In the case of two propellers, both rotating, the advantage of a reduction in the thrust upon the thrust-block is not obtained; and for this reason the addition of fixed guide-blades in place of the second propeller ought to be capable of yielding a higher efficiency.

The first series of experiments, which were carried out with Messrs. Easton and Anderson's steamer Louise, was with a three-bladed propeller, of constant pitch throughout the length of the blades, and not fitted either with a casing surrounding it or with guide-blades abaft it. The following is the mean result of four trials made on the Thames at Long Reach :-

\begin{tabular}{|c|c|c|c|c|c|c|}
\hline Diameter of 1 & Propeller & . & . & . & . & $3 \mathrm{ft} .6 \mathrm{in}$. \\
\hline Mean Pitoh & . $\quad$. & . & . & ** & • & $6 \cdot 35 \mathrm{ft}$ \\
\hline Speed in kno & ts per hour & • & . & . & & $6 \cdot 3$ \\
\hline Indicated $\mathrm{Ho}$ & rse Power & - & . & • & & $21 \cdot 8$ \\
\hline Revolutions o & f propeller & pes & ninute & • & 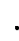 & 156 \\
\hline Slip . & . & . & . & • & • & 33 per cent. \\
\hline Boiler pressu & rre & . & . & . & . & 50 lbs. per sq. in. \\
\hline
\end{tabular}

This propeller was then removed, and replaced by one of rapidly increasing pitch, fitted with casing and guide-blades, the general arrangement and detail of which has been explained and illustrated in Figs. 1 to 4, Plates 76 and 77. Four trials were then made, under circumstances resembling as nearly as possible those of the first series; and the following are the mean results :-

\begin{tabular}{|c|c|c|c|}
\hline Diameter of Propeller & . & . & $3 \mathrm{ft} .6$ in. \\
\hline Pitch . . . & . & & . $5.07 \mathrm{ft}$ to $15.92 \mathrm{ft}$. \\
\hline Speed in knots per hour & . & & $5 \cdot 6$ \\
\hline Indicated Horse Power & . & & . $\quad 13 \cdot 5$ \\
\hline Revolutions of propeller & per minute & & 100 \\
\hline Boiler pressure & . & . & 50 lbs. per sq. in. \\
\hline
\end{tabular}


Assuming that the power required to propel the vessel at speeds of 6.3 and 5.6 knots per hour varies as the cube of the speed-an assumption which is borne out by the experiments made by Mr. Froude on H.M.S. Greyhound,-then the ratio of the efficiencies will be :-

$$
\frac{(6 \cdot 3)^{3} \times 13 \cdot 5}{(5 \cdot 6)^{3} \times 21 \cdot 8}=\frac{3375}{3828}
$$

This shows that 13.4 per cent. increase of efficiency over the ordinary form of propeller has been effected by the alteration in the form of the propeller, with the addition of the guide-blades and of the surrounding cylindrical casing.

The steering properties of this vessel have also been improved by the alteration. Some experiments were made to determine the time required for the vessel under full steam to turn through an entire circle of $360^{\circ}$ when the rudder was placed at an angle of $45^{\circ}$ with the keel. With the ordinary propeller the time occupied was 50 seconds; and with the guide-blade propeller 45 seconds.

The casing surrounding the propeller was next altered, and instead of being made cylindrical was made semi-cylindrical, covering only the upper half of the propeller. In addition there were fitted circular segments, in order to connect this casing with the ship, and form a channel for the supply of water to the propeller. Four trials. were then made, with the following mean results:-

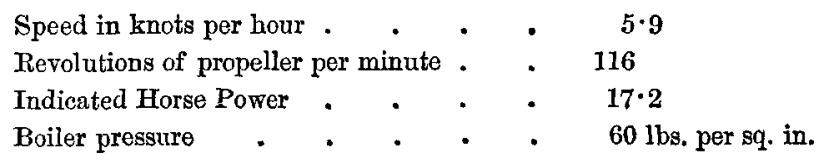

The ratio of efficiencies of the ordinary and the guide-blade propeller is then :-

$$
\frac{(6 \cdot 3)^{3} \times 17 \cdot 2}{(5 \cdot 9)^{3} \times 21 \cdot 8}=\frac{4300}{4477}
$$

showing an increase of efficiency with the guide-blade propeller of only $4 \cdot 1$ per cent.

It is thus seen that the semi-cylindrical casing was not nearly so satisfactory as the former complete cylindrical casing. This was evidently due to the increase of skin friction with the semicylindrical casing, and to the great difficulty in designing the curved 
channel so as to fall in with the stream lines of the water flowing to the propeller; in addition, the path of the water leaving the propeller was not so definite with the semi-cylindrical casing, and some disturbance was produced against the lower guide-blades.

In order to determine, in the experiments with the complete cylindrical casing, whether the water entered the casing with a proper velocity, so as to meet the propeller-blades tangentially to their surface, gauge-glasses were attached to two $\frac{1}{2}$ in. gas pipes, which pointed in the direction of the stream on entering and leaving the propeller respectively, and were capable of being moved opposite different parts of the disc.* The velocities were then determined by the head of water indicated by the gauge-glasses in the cabin. The actual direction of the water leaving the propeller-blades was determined by the same means. When these experiments were worked out, it was found that the errors in designing the angles of the propeller and guide-blades were very slight indeed.

In a paper read before the Institution of Naval Architects by Mr. W. H. White (Transactions, 1878, p. 36) it is stated that one of the advantages possessed. by twin over single propellers is that it is possible to obtain a larger disc area with the former than with the latter; and consequently, in cases where it is essential to obtain high speeds, it is preferable to use two screws, in order to absorb the maximum horse-power with the greatest amount of efficiency. In the case of the propeller fitted with guide-blades, it is possible, by slightly increasing the pitch, and arranging the angles of the guideblades to suit, to keep under control the revolutions of the propeller, notwithstanding that the horse-power of the engines be considerably increased. In vessels of shallow draught also, where it is impossible to obtain a propeller sufficiently large in diameter for the required disc area, a propeller of this construction could be very advantageously used. One remarkable peculiarity of this propeller is the sudden grip which it takes of the water immediately on being started : no churning being observed, as is the case with ordinary propellers.

* See Discussion, p. 604-605, for fuller explanation. 
From what has been said, it will now be seen what are the essential features of the propeller under consideration. From the approximate investigation of the loss by friction upon the surface of the propeller-blades, it has been shown that this loss amounts, with the ordinary propeller, to something very considerable; and it has been the author's aim to diminish it, if possible, by reducing the speed of the propeller-blades. In the late Mr. Froude's recent investigations upon this subject, he found that it is advantageous to increase the pitch of the propeller-blades considerably, so as to produce a slip of from 30 to 40 per cent. The beneficial results obtained by him from this alteration seem to have been due to a reduction of skin friction upon the blades.

With reference to the construction of a propeller of the kind now described, the blades, being helical surfaces of rapidly increasing pitch, can be bent out of sheet steel previously cut to the required shape, and either thickened up so as to enable them to be keyed into the central boss, or flanged so as to be screwed to it. They can also be made thinner than ordinary propeller-blades, in consequence of their possessing greater stiffness due to their increasing pitch. The guide-blades also, being surfaces of the same description as the propeller-blades, and at the same time being supported at their extremities by the casing surrounding them, can be made very thin; and the resistance to the passage of the water through them will be little more than that due to their skin friction.

In carrying out the modifications suggested, there are of course many serious questions involved, which it is out of the province of the present paper to discuss; and in laying the preceding results before this Institution the author has been desirous rather to point out a somewhat new aspect under which the screw-propeller may be considered, than in any way to bring forward an exhaustive investigation of the principles involved. Although the results of these experiments show an improvement as regards efficiency, still the trials were made under circumstances which were not entirely conclusive in favour of the new propeller. For a conclusive experiment, either the speeds of the ship with the ordinary and the 
new propeller should have been the same and the comparative horse-powers should have been registered, or the horse-powers should have been the same and the comparative speeds of the ship should have been registered. These conditions unfortunately could not be obtained in the case of the steamer experimented upon. The author is of opinion however that, in order to improve the efficiency of the screw-propeller, some contrivance must be found which shall reduce the loss by friction of the blades through the water. This reduction cannot be effected by any modification in their shape, except at the expense of producing a great rotary motion of the water by an increase in the pitch. The question of how to deal with this rotary motion is therefore of much scientific and practical interest; and it is mainly in the hope of having it fully discussed that the author has brought forward the present paper.

\section{Discussion.}

Mr. Parsons wished to say a few words in regard to the present state of the question. After the experiments which had been described in the paper had been carried out, he had laid the matter before the Admiralty, thinking they might feel inclined to make some further experiments upon the subject. Mr. Barnaby, the Chief Constructor, and Mr. Wright, the Chief Engineer of the Admiralty, then inspected the vessel under steam; and their impression with regard to the propeller, as far as they had the opportunity of seeing it, was that it worked very satisfactorily. They subsequently recommended a further investigation to be made; but before it was carried out on a large scale, they proposed (and he fully concurred with them) that the matter should be referred to the late Mr. Froude for investigation at Torquay with his models. Owing to his ill health and subsequent 
lamented death, the matter dropped for a time; but about three weeks ago he received a letter from the Admiralty stating that they had placed the matter in the hands of Mr. Froude's son (Mr. Edmund Froude), and that before long some investigations would be carried out at Torquay.

He had lately made some more experiments with regard to the friction of the casing, and also with regard to the guide-blades. It had been frequently urged that the loss, or the drag on the ship, due to the friction of the casing and also of the guide-blades, was more than was made up by the forward thrust given by the guide-blades. Feeling sure, from the experiments carried out upon the Louise, as described in the paper, and also from Mr. Griffiths' experiments with a casing, that there must be a positive advantage both from the guideblades and from the casing, he had altered his model into the form now exhibited, as shown in Fig. 6, Plate 78, in order to test this point. Here the propellex shaft A was prolonged backwards, and carried in a bearing $B$ at its after extremity; while the casing and guide-blades $\mathrm{C}$, instead of being fixed in their proper position relatively to the propeller $P$, as indicated by the dotted lines, were mounted loose on the shaft, so as to be capable of travelling backwards into the extreme position shown by the full lines, wholly abaft of the propeller-blades, which would then rotate in open water. The casing was prevented from rotating by a cord, which however left it free to travel endways along the shaft. The casing was first placed in its proper position over the propeller-blades, as indicated by the dotted lines; and the propeller was driven at full speed until the whole of the water in the trough was set in motion in the direction of the arrows, the velocity of the current then representing the speed of the supposed vessel through the water. The propeller being now suddenly stopped, while the current continued flowing, it was seen that the casing and guide-blades were at once carried bodily backwards by the stream into the position shown by the full lines; this end movement represented therefore the drag of the water upon the casing and guide-blades in a steamer moving through the water. But on setting the propeller in motion again in the same direction as at first, while the original current still continued flowing, it was seen 
that the casing, instead of remaining in the rear of the propeller, was drawn forwards again into its proper position over the propeller blades, as shown by the dotted lines; this forward movement represented the net amount of the forward thrust imparted by the guide-blades to the vessel, and proved conclusively that the forward thrust was in excess of the drag. Hence the ship was accelerated by the thrust of the guide-blades much more than it was retarded by the drag attending the motion of the casing and guide-blades through the water.

He had omitted to mention in the paper that the action of the propeller in going astern, though, as with all propellers, it was not as good as in going ahead, was very fair, and was sufficient to steer the vessel very tolerably. It would be seen that with a propeller of this kind it was a reduction in the speed of revolution which gave the increased efficiency. Now all who were conversant with marine engines knew that it was a great disadvantage to reduce the speed of the engines. The late Mr. Froude, who was fully aware of the advantage of reducing the speed of the propeller, had told him (Mr. Parsons), in speaking of experiments made upon the Iris, that the great advantage shown in the second trial was gained by increasing the pitch of the propeller and diminishing its diameter. By increasing the pitch he obtained more slip; and by diminishing the diameter he obtained less friction on the blades. He said also that he hoped marine engineers would adopt in the future a larger number of engines running at a higher speed, and would gear them to the propeller shaft. Now the great advantage which had been obtained by getting rid of gearing in the marine engines of the present day was generally admitted; and therefore the re-introduction of gearing was a matter open to discussion. But it could be shown that advantage might also be gained by reducing the diameter of the propeller, no less than by diminishing its speed. Taking the Lord Clyde as an instance, he found that by reducing the diameter of the propeller from $23 \mathrm{ft}$. to $19 \mathrm{ft}$. the skin friction of the blades would be reduced by about one half. Of course by diminishing the diameter of the propeller the disc area would be diminished, and consequently the slip would be increased. But the area of a disc $23 \mathrm{ft}$. diam. was $415 \mathrm{sq}$. ft., and 
of one $19 \mathrm{ft}$. diam. $283 \mathrm{sq}$. ft., so that one was only a third smaller than the other, and the slip would be increased in that ratio. In some instances that reduction of diameter might be of great value, especially in light-draught vessels or torpedo boats, where a large proportion of the diameter of the propeller was sometimes out of the water, the slip in that case being of course very large.

There was one other point to be mentioned, namely the distance which it was possible to put between the propeller-blades and the guide-blades. M. Debay had been making some experiments with two propellers working one into the other, and revolving in opposite directions; the blades were cut into the form of a comb, and the teeth of the two combs passed one through the other. With that method however a small piece of wood getting in between the teeth of the comb would damage the propeller at once. In the case of the propeller described in the paper, the model clearly illustrated that it was not important for its efficient working that the guide-blades should be placed close abaft the propeller; and consequently, should anything by chance get in between the blades, the probability of their being damaged would be very small.

Mr. Wu. Aroenson said that the idea of improving the screw propeller had arisen from the experiments which Mr. Parsons had carried out for him upon so-called centrifugal pumps. The fact. was that turbines with guide-curves, centrifugal pumps, and screw propellers with or without guide-curves, ought all to be investigated in the same manner, becanse they formed varieties of the same species of machinery. The screw propeller without guide-curves, or without a counter screw revolving in the opposite direction, was really a turbine without guide-curves; and everyone knew that such a turbine did very bad duty comparatively. There could be no question that the plan of giving a rotatory motion to the water, with the intention, afterwards of taking up that rotatory motion by guide-curves, if properly carried out, would result in very great advantage ; and it was much to be regretted that the death of $\mathrm{Mr}$. Froude had caused delay in the experiments which were to have been carried out at Torquay. Mr. Parsons had touched upon one point requiring investigation, 
namely the distance at which the guide-blades could be placed from the propeller-blades. The objection often raised to the arrangement was that the close proximity of the two would cause danger from obstacles getting in between them; but if it could be shown that the distance might be increased to the distance which now existed between the stern post and the propeller, that objection would come to an end.

He was sorry that the author had not explained more clearly the reason why the Louise, on which the experiment was tried, could not be driven at full power with the improved propeller, as compared with the original propeller. The reason was that the increased pitch of the improved screw necessarily obliged the engine to go at a slower speed, because the resistance was greater; and the engine could not of course develop the same horse-power per minute at the slower speed which it had developed at a higher speed, as long as the steam pressure was the same. The only way of getting over the diffeulty would have been to put in larger cylinders, or to get a higher pressure in the boiler. It was not convenient to put in larger eylinders; and they could not get a higher pressure because the boiler was rather old, and it was not thought safe to go beyond $60 \mathrm{lbs}$. pressure. That was the reason why, instead of giving the absolute power developed for a certain speed, Mr. Parsons had been obliged to estimate what the power would have been, supposing the boat had run at the same rate under both conditions.

One rather curious point had come out in regard to Mr. Froude's experiments on the friction of screw-propeller blades. It appeared that the experiments made by Mr. Froude were with water passing over surfaces covered with fine sand. On reducing those experiments he found that they gave $3.34 \mathrm{lbs}$. per sq. $\mathrm{ft}$. of water friction, at $22 \mathrm{ft}$. per second or 15 miles an hour. Now the figure derived from the ordinary formula for water friction in cast-iron pipes was 3 lbs. per sq. ft., so that there was a difference of only $0.34 \mathrm{lb}$. between Mr. Froude's experiments and those with reference to the friction of water in pipes.

It appeared to him that the question of the proper shape of the propeller would be a very good subject of research for the Institution. It would be very profitable to collect all the literature and all the 
experiments upon the subject, before more money was spent upon making experiments which had been often tried in various forms by others, but had never yielded any practical result.

Professor Osbonne Rexnouns wished to ask Mr. Parsons one or two questions with regard to his experiments. The first question was whether Fig. 4, Plate 77, bore any relation to the actual form and position of the blades as they were working. It seemed to him that the obliquity of the guide-blade to the propeller-blade was very great, as compared with any lateral motion that the water could possibly have imparted to it from the screw.

Mr. Parsons said Fig. 4 was correctly drawn to scale. After the first few trials had been carried out upon the Louise, and it was ascertained that an improvement in the efficiency had been obtained, it was thought advisable to determine whether the angles of the propeller-blades and also of the guide-blades were designed so as to meet the water in a direction tangential to their surface, thereby producing as little disturbance as possible to the passage of the water. For this purpose $\frac{1}{2}$-inch pipes $a b c$ and $d e$, Fig. 8, Plate 78, were attached to the forward end of the casing and were used in the following way. The pipe $d e$ was a plain vertical pipe open to the water at point $d$, at the entrance to the casing and on the level of the shaft; on the other end $e$, within the vessel, was a gauge-glass. The level of the water in this gauge-glass gave within the vessel the statical pressure of the water at its entrance to the casing. The pipe $a b c$ was fitted with stop-cocks at $a$ and $b$, pointing in the direction of the stream, and was fitted at the end $c$ with a gaugeglass. By keeping the cock $a$ closed and $b$ open, while the vessel was in motion, and measuring the difference in height of the columns in the gauge-glasses $c$ and $e$, it was possible to determine the velocity of the current entering the casing at the top. Similarly by closing $b$ and opening $a$, the velocity of the current entering on the lower side of the propeller was also determined. A similar series of experiments were also carried out at the after end of the casing, as. shown by the pipes $f g h$ and $k l$. 


\title{
ON FIRELESS LOCOMOTIVES FOR TRAMTWAYS.
}

\author{
By M. LÉON FRaNCQ, of PAris.
}

Engineers have yet to solve the problem of discovering the most suitable motive-power for the purpose of traction on tramways. Its solution is the more important because it must also settle the question of the transport and utilisation of steam in places where engines provided with furnaces are inapplicable. Having made a particular study of engines designed for traction, the author has been led to believe that the problem may be solved, in the case of tramways at least, by the use of a Fireless Engine, such as will now bo described.

The great expense involved in the working of tramways, due first to the nature of the permanent way, and secondly to the high cost of horse traction, has proved in many cases a serious bar to their success. If mechanical traction be used, it is necessary that the line be kept in better order than it is generally; and the excess of expense thus required for the line must be made up by the greater economy in the motive power. This economy can only be attained by reductions in wages, in consumption of fuel \&c., in maintenance and renewal expenses of the road and rolling stock, and.in the first cost of the mechanical power.

It is further essential, at least in towns, that the questions of safety and health be taken into consideration. To arrive at that result it is necessary to avoid the use of ordinary engines subject to the chance of explosion, and to the throwing off of sparks. The light of the fire must not be seen, and cinders must not be scattered upon the highway. The noise occasioned by safety-valves must be suppressed, as well as that produced by the blast. Lastly, all escape of smoke, soot, or noxious gas must be done away with. 
any calculations were of value unless they were backed up by experiments. As indicating the best experiments to be tried, calculations were valuable; but by themselves they did not stand for very much. But Mr. Parsons had two distinct modifications in his design, one the use of guide-blades, and the other the increase of pitch. Hence, if there was any improvement, to which of these was it really due? It appeared to him that in making the experiments the best way would have been to separate the two modifications and try one at a time.

With regard to the movable casing in the model running forwards bodily, as soon as the propeller was started again after standing still while the water was running past it, he thought that it might be due to another cause than pressure on the guide-blades. The pressure of the water running through the casing was diminished in proportion to the rapidity of the motion; so that the casing would be like a tapering vessel, with a smaller pressure inside than outside: therefore it would be in a state of suction forward towards the larger end, and consequently would tend to run forward over the propeller, until the motion imparted by the propeller to the water had to a great extent ceased.

With regard to Mr. Froude's experiments on the Iris, which Mr. Parsons had mentioned, he did not think that the result of those experiments should be taken as affording a conclusive proof of the greater skin-resistance with the larger propeller. There were many things in the screw propeller that were not thoroughly understood; and it seemed to him quite possible that all the loss which was found with large propellers might be due entirely to the stream-line motion of the water round the ship being different on one part of the propeller from what it was on another, and might not be due to skin-resistance at all.

Mr. Andenson asked permission to say, in reply to Prof. Reynolds' question about the particular propeller which was fitted to the Louise before Mr. Parsons began to make his experiments, that this propeller was one of three cast-iron propellers of various pitches and forms, made by his firm in order to try and get the best shape for that 
particular boat. The pitch had not been arrived at by any mathematical investigation, but it was the one that had been found to answer best in driving the vessel.

Mr. E. A. CowPER had always been a strong adrocate of "increasing pitch" for the blades of propellers. He wished to know what was the increase in the pitch of the old screw of the Louise. It was stated on p. 595 of the paper that the mean pitch was $6.35 \mathrm{ft}$.; but according to all that he had learned and tried he did not think any uniform pitch the best. There should be a decided increase in the pitch from the fore to the after end of the blades, in order to obtain the best results out of an ordinary serew. Therefore he did not think that the experiment had been tried as against the best common serew. He partly agreed with what Professor Reynolds had said in reference to the very sharp angle between the propeller and guide-blade, Fig. 4, Plate 77; but he could quite believe that the direction taken by the water was exactly as given by Mr. Parsons; for the rotation of the water with a screw propeller driven at anything like a high velocity was very serious, and for such an extraordinary pitch as $15.92 \mathrm{ft}$. for a $3 \mathrm{ft} .6 \mathrm{in}$. screw, the rotation must have been excessive. What ought to have been done, in order to make the trial a fair one between the two screws, would have been to reduce the diameter of the new screw from $3 \mathrm{ft} .6$ in. down to perhaps $3 \mathrm{ft}$., or, better still, to reduce the excessive pitch, and then let the engine run faster, so as to get 156 revolutions per minute as before, thus developing the same horse-power with the new serew as with the old one. The boat would then have gone much faster than 5.6 knots per hour with the new screw, and probably would have exceeded the speed obtained, with the old screw.

Mr. Jam Waston asked whether the experiment with the new screw was tried without a casing.

Mr. Parsons said in reply that the new propeller was always fitted with a casing. In the earlier experiments an immense amount 
of air was drawn down in front of the casing just at starting. That did not continue when the vessel was fairly under weigh; and it was prevented even at starting by prolonging the upper part of the casing forward to meet the hull, as shown by the dotted lines at $K$ in Fig. 1, Plate 76. The air was then prevented from going down, and there was no eddy or disturbance whatever behind the stern; so that one would think that the ressel was sailing. It was this stillness that had attracted Mr. Barnaby's attention more than anything else about the trial. With the old propeller there was a good deal of disturbance, as in the case of most vessels; but it was not immersed very deep, not more than six or eight inches. The new one was immersed only six inches; yet when it was running at full speed there. was no air whatever drawn down.

Professor Reynouds said Mr. Thornycroft had also found that a casing stopped the air from being drawn down, which was a very great advantage.

Mr. Parsons said that with regard to increasing pitch for the propeller-blades a great many experiments had from time to time been tried; but curiously enough the propellers which were at present most in vogue with the Admiralty were those of Mr. Griffiths and Mr. Hirsch, and they were both of constant pitch. Both of them were curved in their radial direction, Mr. Griffiths' having the curve backward and Mr. Hirsch's the curve forward. Some years ago he believed Mr. Imray had tried some experiments with a propeller of increasing pitch, and had found that the increasing pitch was certainly an advantage.

With regard to Professor Reynolds' suggestion as to the cause of the morable casing in the model, to which the guide-blades were attached, closing up to the propeller when the propeller was rotated, he might mention that the same effect had been found to take place with a cylindrical casing; and that the taper of the bell-mouthed. casing in the model was so small that it could scarcely have any influence. 
The Presionar said they were all very much obliged to $\mathrm{Mr}$. Parsons for bringing that important question before the meeting. The only regret of the Council was that the paper had not been read in Glasgow, where of course the opportunities for discussion and reply would have been more favourable than in Manchester. He agreed with Professor Reynolds in his suggestion that, if there were three arrangements tried together, it was very difficult to say to which any benefit gained was attributable. In this instance there was first the casing, secondly the increasing pitch in the propeller-blades, and thirdly the guide-blades. Therefore he hoped that, when $\mathrm{Mr}$. Froude, Jun., tried his experiments for the Admiralty, he would see what result could be obtained from each one of those arrangements separately. With regard to the suggestion that the Research Committee might advantageously undertake such a set of experiments, the subject appeared to him to belong rather to the Institution of Naval Architects than to themselves, and perbaps still more to the Government, who were more interested than anyone else in the question. He asked the Members to give a vote of thanks to Mr. Parsons for his paper.

The rote of thanks was passed.

The following paper was then read:- 


\section{GUIDE-BLADE SCREW PROPELLER. Plaze76.}

Fix. 1. Longikudinal Section through Propeller \& Guide Blades.

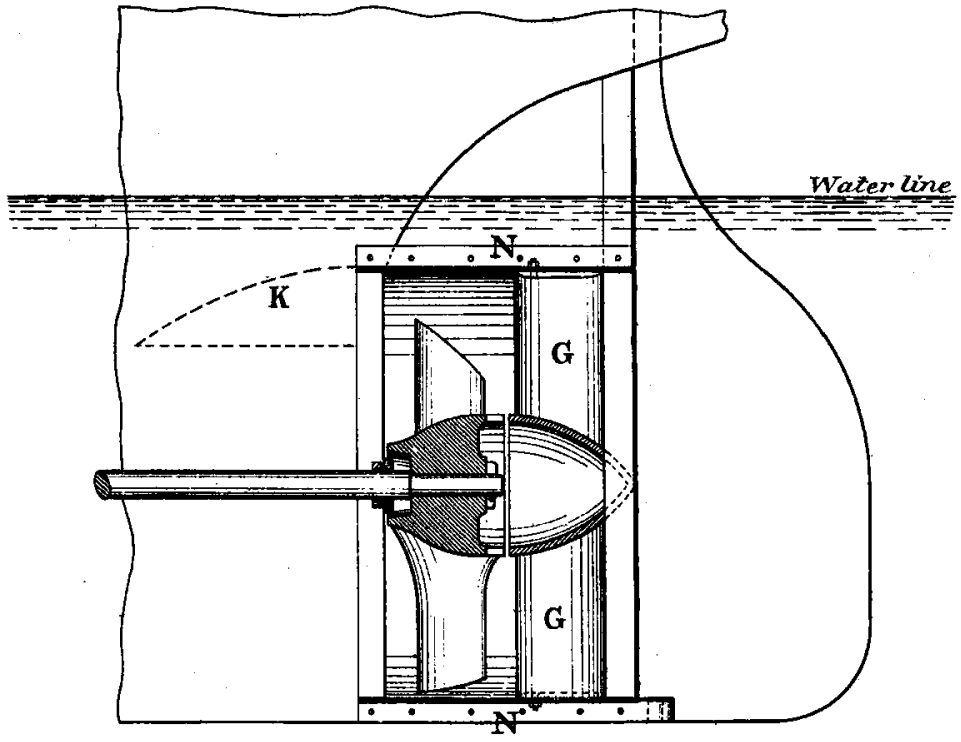

Fig: 2. Propeller.

Fig: 3. Auide Blade.
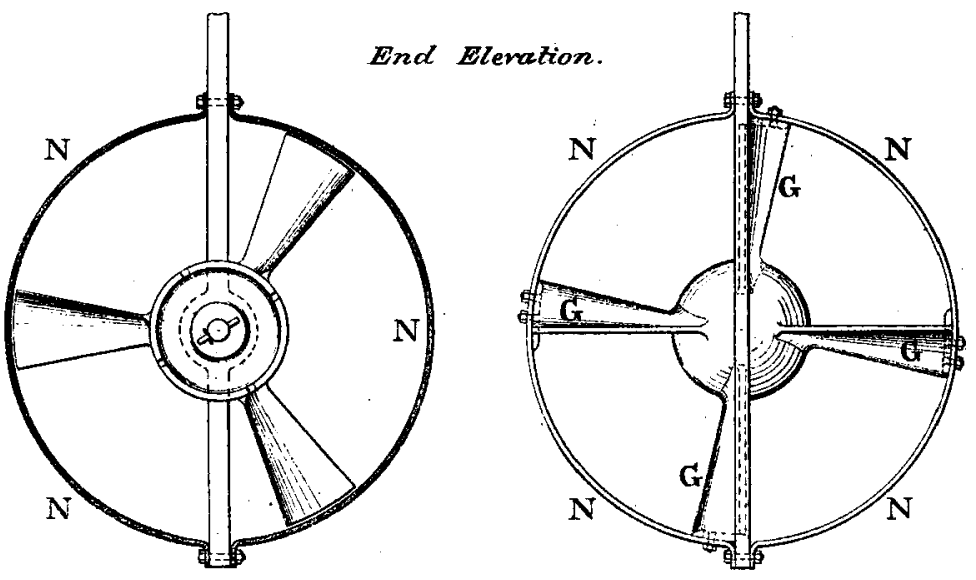

Scale $1 / 24^{\text {th }}$

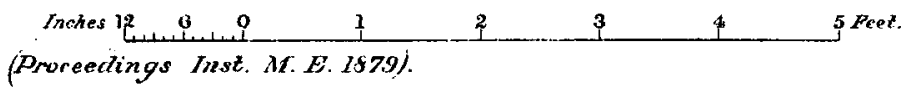




\section{GUIDE-BLADE SCREW PROPELLER.Plate77.}

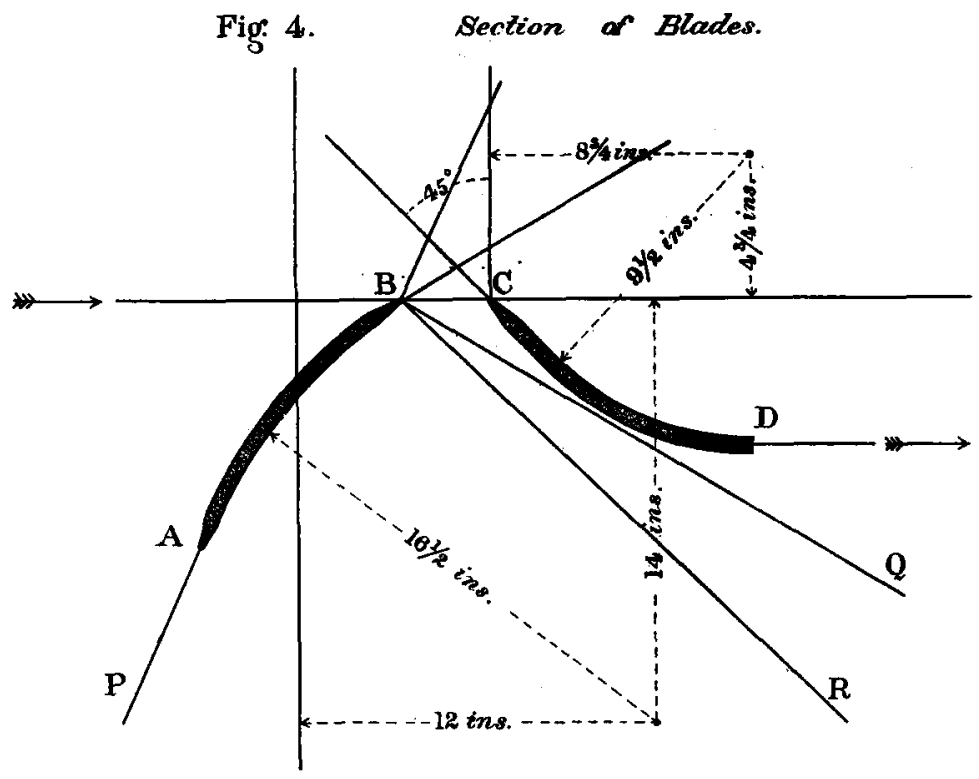

Fig: 5. Diagram of slip of Propeller.

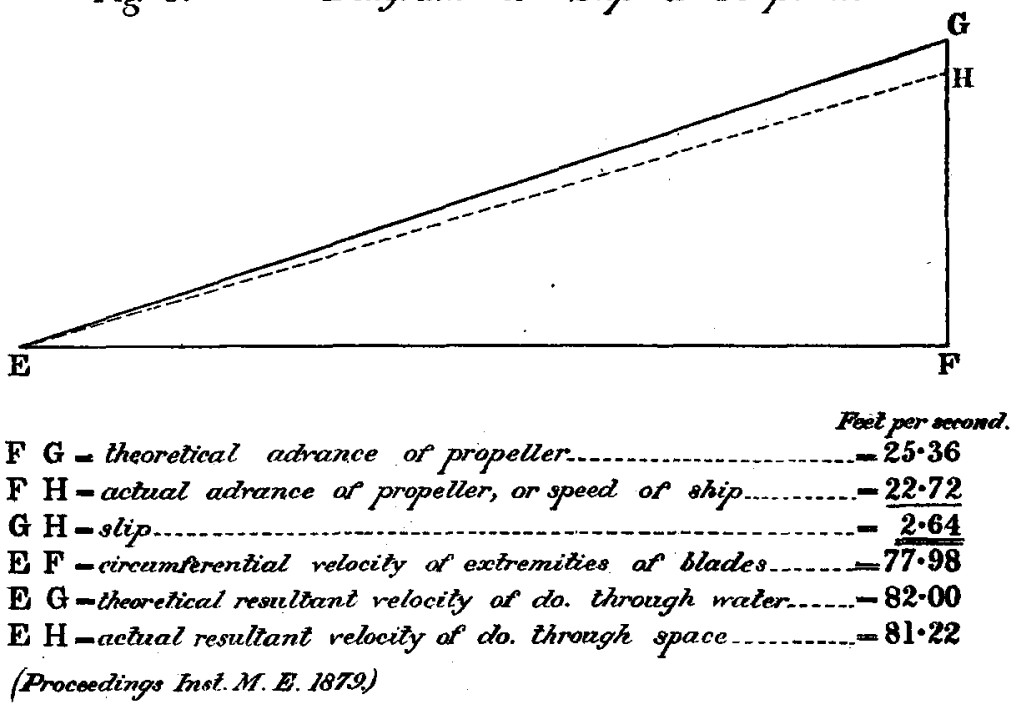


GUIDE-BLADE SCREW PROPELLER. Plate 78.

Fig. 6. Plan of experimental Model in mater trough.

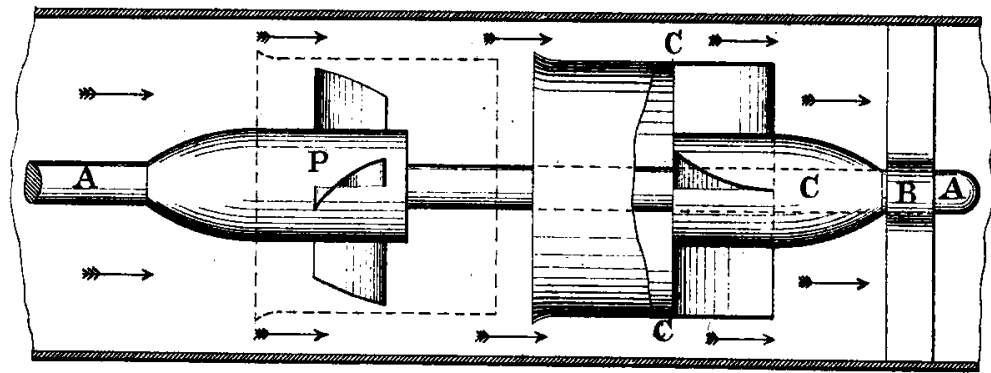

Determination of Angles for Blades.

Fig. 7.

Fig. 8.

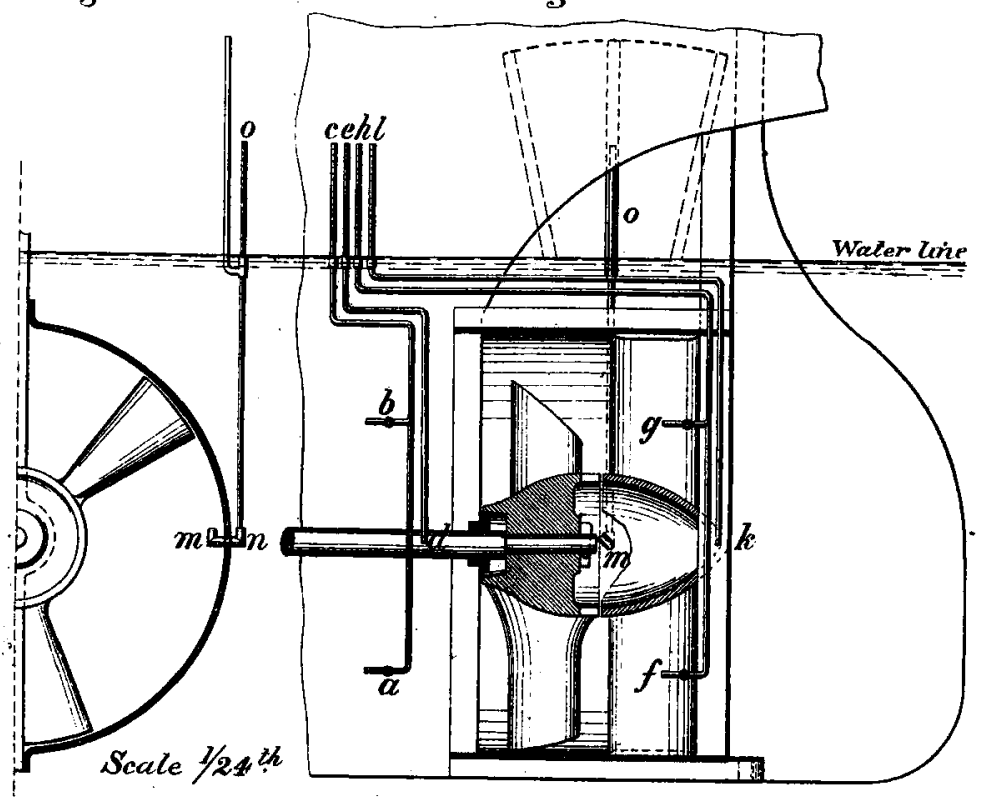

(Proceedings Inst. M.E. 1879.) 